\title{
Violence and verbal abuse against staff in accident and emergency departments: a survey of consultants in the UK and the Republic of Ireland
}

\author{
Mark G Jenkins, Laurence G Rocke, Brian P McNicholl, Declan M Hughes
}

\begin{abstract}
Objectives-to determine the incidence of verbal abuse and physical violence in accident and emergency (A\&E) departments and to discover the extent of provision of security measures and instructions for staff on how to deal with these problems.

Design-A postal questionnaire.

Setting-A\&E departments in the UK and the Republic of Ireland.

Subjects-Two hundred and seventy three consultants named in charge of $310 \mathrm{de}-$ partments.

Main outcome measures-Frequency of physical violence and verbal abuse, injuries sustained, perceived precipitating factors, security measures instituted, and legal action taken.

Results-Two hundred and thirty three replies were received. Alcohol, waiting times, recreational drug usage, and patients' expectations were perceived as the chief causes. Patients were the chief perpetrators with nurses being the commonest victims. Staff sustained 10 fractures, 42 lacerations, and 505 soft tissue injuries. There were 298 arrests and 101 court appearances that resulted in 76 convictions. Panic buttons and video cameras were the most common security measures. Conclusions-Staff within A\&E departments are regularly abused, both verbally and physically. Inner city departments appear to be most affected. Documentation is poor. Perpetrators are seldom convicted. There do appear to be actions which hospitals could undertake that might help to ameliorate these problems. ( $₹$ Accid Emerg Med 1998;15:262-265)
\end{abstract}

Keywords: violence; verbal abuse; security; staff

\section{Accident and Emergency Department, Royal Victoria Hospital, Grosvenor Road, Belfast, Northern Ireland BT12 6BA $M$ G Jenkins L G Rocke B P McNicholl $D M$ Hughes}

Correspondence to: Dr Jenkins.

Accepted for publication 16 March 1998
There is some research and there have been anecdotal reports in the press of numbers of incidents that suggest that violence and verbal abuse against staff in accident and emergency (A\&E) departments are problems. ${ }^{1-3}$ The magnitude is unknown within the UK and the Republic of Ireland. The security measures and departmental policies used to try to support and safeguard staff have not been quantified.

The purpose of this survey was an attempt to do this, in the hope that it would help demonstrate the scale of the problem, thereby supporting $A \& E$ department staff in their efforts to secure safer working environments, and provide a yardstick by which any further increase in violence and abuse could be measured.

\section{Subjects and methods}

A questionnaire was sent to $310 \mathrm{~A} \& \mathrm{E}$ departments throughout the UK and Republic of Ireland, representing a total of 273 consultants in A\&E medicine. After six weeks, a second questionnaire was sent to those departments that had failed to reply initially.

Respondents were asked to indicate the annual number of new attendances, the department type (inner city/urban/country), and the number and type of standard security methods in current use. They were asked to try to assess their staffs' perceptions as to how safe or vulnerable they felt at work.

All respondents were asked to enumerate, as accurately as possible, the number of episodes of verbal and physical abuse in the previous year from their records, to indicate the frequency of verbal and physical abuse, that is daily, weekly, etc, to identify the nature of physical injuries sustained, to indicate the types of staff most commonly in receipt of abuse, and which members of the public were most likely to behave in an abusive manner.

They were asked to describe departmental policy for recording and dealing with incidents and to indicate if any legal or civil action had been undertaken by trusts to support staff and prosecute offenders. They were also asked to indicate why they thought abuse occurred and to give an opinion as to possible measures that could be taken to try to alleviate these problems if, indeed, problems of this nature were found to be widespread. They were also asked to indicate the effect that abuse had on staff morale.

\section{Results}

Of the 310 departments mailed replies were received from $233(75 \%)$ departments, involving $219(80 \%)$ consultants. Department types were given as follows: 53 country (23\%), 50 inner city $(17 \%), 117$ urban $(50 \%)$, two inner city/urban, and eight (3\%) urban/country. Three departments did not categorise themselves.

Table 1 indicates the security measures in use and the frequency with which departments availed themselves of them. Panic buttons were present in 166 (71\%) A\&E departments, video cameras in $150(64 \%)$, and security guards in $114(49 \%)$. Personal alarms were issued in 89 (38\%) departments; direct police alarms were 
Table 1 Breakdown of security measures within departments

\begin{tabular}{|c|c|c|c|c|c|c|c|}
\hline & \multicolumn{7}{|c|}{ No of security measures } \\
\hline & 0 & 1 & 2 & 3 & 4 & 5 & 6 \\
\hline Hospital departments & 14 & 34 & 63 & 67 & 44 & 9 & 1 \\
\hline \multicolumn{8}{|l|}{ Security measure } \\
\hline Police alarm & 0 & 0 & 8 & 17 & 26 & 9 & 1 \\
\hline Personal alarm & 0 & 4 & 18 & 32 & 26 & 8 & 1 \\
\hline Panic button & 0 & 17 & 43 & 54 & 41 & 9 & 1 \\
\hline Closed circuit TV & 0 & 5 & 33 & 59 & 43 & 9 & 1 \\
\hline Security guard & 0 & 8 & 23 & 38 & 35 & 8 & 1 \\
\hline Police on site & 0 & 0 & 1 & 1 & 5 & 2 & 1 \\
\hline
\end{tabular}

in $61(26 \%)$, and on site police in $10(4 \%)$. Fourteen (6\%) A\&E departments had none of the above security measures whereas only one department had all six measures.

Only five $(2 \%)$ departments rated their security systems as very effective. Altogether $110(47 \%)$ departments felt that their security was effective, 14 (6\%) departments rated security as between effective and poor, and 99 $(42 \%)$ said it was poor. Only four $(2 \%)$ respondents rated their departments as very safe, $53(23 \%)$ felt safe, $23(10 \%)$ felt safe to vulnerable, $142(61 \%)$ felt vulnerable, and eight $(3 \%)$ felt very insecure.

When comparing levels of abuse against staff with those of five years before, $197(85 \%)$ felt that verbal abuse was increasing, $30(13 \%)$ said it was the same, and just one felt it was decreasing. Concerning physical violence, 140 $(60 \%)$ felt it was increasing, $84(36 \%)$ indicated it was the same, and three $(1 \%)$ thought it had decreased.

Incidents of verbal abuse were always recorded by $39(17 \%)$ of $A \& E$ departments, sometimes by 107 (45\%), occasionally by 69 $(30 \%)$, and never by $16(7 \%)$. Seventy seven (33\%) departments had guidelines for dealing with this problem but $146(63 \%)$ had no such documentation.

A total of $179(77 \%)$ departments always recorded episodes of physical violence, 33 (14\%) usually, 13 (6\%) occasionally, and one never. Written guidelines for the management of physical violence were present in 137 (59\%) departments. Seventy nine departments (34\%) had no written policy.

Thirty eight (16\%) departments said that verbal abuse was occurring several times per day, 81 (35\%) daily, 77 (33\%) weekly, with nine $(4 \%)$ somewhere in between. Eighteen (8\%) departments replied that it occurred monthly and six (3\%) had it occurring less often than this.

Physical violence occurred several times daily in only one department. Five (2\%) departments had it occurring daily and 29 $(12 \%)$ on a weekly basis. Monthly (approxi- mately) episodes of violence were registered in $119(51 \%)$ departments. Physical violence less than monthly occurred in 45 (19\%) departments with 30 (12\%) departments reporting that they had no violence whatsoever. Of departments reporting no violence, five had no security measures, seven had one, 10 had two, seven had three, and one had four of the security measures.

Actual numbers of episodes of verbal abuse given for the previous year were totalled as 12477 . There were 1444 recorded episodes of physical violence in that year.

Injuries sustained by $A \& E$ staff in these episodes included 10 fractures, 42 lacerations, and 505 soft tissue injuries. One hundred and six episodes resulted in staff taking time off work. There were 298 arrests, 101 court cases, 46 impending court cases, and a total of 76 convictions.

The incidence of verbal abuse and violent episodes per new patient attendance (in departments recording incidents) in relation to the number of security measures in place is shown in table 2 . This fails to show any direct correlation between the number of security measures in place and levels of violence and abuse. Speculation that increased levels of visible security actually lead to an increase in the incidence of abuse, whether verbal or physical, would therefore seem to be unfounded.

Although there were large regional variations in the reported incidence, both types of abuse appeared to be a problem for all areas. The one exception was Wales, where both physical and verbal abuse seemed to be significantly lower than anywhere else. The reason for this is unclear but the response rate from Wales was somewhat lower than other areas; in addition, rates of recording or type of departments may differ from other areas.

Of more interest were the results in terms of department type (tables 3 and 4). Table 3 shows a clearly increasing trend for verbal abuse from rural to inner city departments. Table 4 shows that the incidence of physical violence does not differ to any extent between rural and urban departments but that inner city departments are much more badly affected. Even allowing for variations in recording episodes, these figures are compelling and do suggest that inner city departments are much worse for both types of abuse.

By some way, nurses were most commonly the recipients of verbal abuse, then receptionists, doctors, and other patients in descending order of frequency. The descending order of frequency of recipients of physical violence was nurse, doctor, receptionist, and other patients.

Table 2 Incidence of episodes of verbal abuse and physical violence per new patients related to security measures

\begin{tabular}{|c|c|c|c|c|c|c|c|}
\hline & \multicolumn{7}{|c|}{ No of security measures } \\
\hline & 0 & 1 & 2 & 3 & 4 & 5 & 6 \\
\hline Hospital departments & 14 & 34 & 63 & 67 & 44 & 9 & 1 \\
\hline Total new patients & 428000 & 1170838 & 2585749 & 3369954 & 2188904 & 503000 & 86000 \\
\hline $\begin{array}{l}\text { Incidence of verbal abuse per new patient } \\
\text { seen (in departments keeping records) }\end{array}$ & $1 / 1480$ & $1 / 653$ & $1 / 369$ & $1 / 671$ & $1 / 278$ & $1 / 2253$ & Not known \\
\hline $\begin{array}{l}\text { Incidence of physical abuse per new patient } \\
\text { seen (in departments keeping records) }\end{array}$ & $1 / 11692$ & $1 / 9910$ & $1 / 9488$ & $1 / 7979$ & $1 / 1973$ & $1 / 7196$ & $1 / 3583$ \\
\hline
\end{tabular}


Table 3 Department type and verbal abuse (only departments specifying their type have been used)

\begin{tabular}{|c|c|c|c|}
\hline & \multicolumn{3}{|c|}{ Type of department } \\
\hline & Rural & Urban & Inner city \\
\hline Departments recordings & 21 & 57 & 27 \\
\hline New patients seen in these departments & 1256024 & 5066144 & 2709363 \\
\hline Episodes recorded & 1138 & 5964 & 5072 \\
\hline Episodes per department & 54 & 104 & 187 \\
\hline
\end{tabular}

Rural $v$ inner city, $\mathrm{p}=0.0000$; rural $v$ urban, $\mathrm{p}=0.005$; inner city $v$ urban, $\mathrm{p}=0.002$.

Table 4 Department type and physical abuse (only departments specifying their type have been used)

\begin{tabular}{lrrr}
\hline & \multicolumn{3}{l}{ Type of department } \\
\cline { 2 - 4 } & Rural & Urban & Inner city \\
\hline Departments recordings & 27 & 79 & 29 \\
New patients seen in these departments & 1297024 & 5496058 & 2810863 \\
Episodes recorded & 145 & 508 & 730 \\
Episodes per department & 5 & 6 & 25 \\
\hline
\end{tabular}

Rural $v$ inner city, $\mathrm{p}=0.0000$; rural $v$ urban, $\mathrm{p}=0.45$; inner city $v$ urban, $\mathrm{p}=0.0000$.

The most likely perpetrator of assault was the patient, followed by friends, then relatives. The great majority of respondents felt that alcohol $(98 \%)$ was the most significant precipitant of abusive behaviour (table 5), followed by long waiting times, then drug abuse. Significant numbers felt that patients' expectations and the patient's charter were also important in this respect.

It was felt that staff morale had fallen as compared with five years ago in $139(60 \%)$ A\&E departments. Rising morale was reported in $34(15 \%)$ departments and $64(27 \%)$ departments indicated that they felt staff morale was similar to that five years ago. Almost $90 \%$ of respondents felt that these problems of abuse were relevant to staff morale, $91(39 \%)$ in a major and $112(48 \%)$ in a minor way. Twenty seven $(12 \%)$ felt they were negligible.

There were a variety of suggestions for possible courses of action to try to relieve these problems. The most common idea $(n=45)$ was to improve security by a visible presence of police and/or security guards. Next $(n=37)$ was the idea of a campaign of patient re-education as to the role of $A \& E$ departments, along with the promotion of a staff charter. Increasing staffing levels $(n=37)$ to reduce waiting times was an equally popular idea. Some $(n=30)$ felt it important to try to increase the awareness of management about these problems and have them institute policies to vigorously pursue and, where appropriate, prosecute offenders. Two respondents said they felt that the presence of guard dogs would be an effective deterrent.

Table 5 Precipitating factors and the number (\%) agreeing with these

\begin{tabular}{ll}
\hline Precipitating factor & No (\%) agreeing \\
\hline Alcohol & $228(98)$ \\
Waiting times & $200(86)$ \\
Drugs & $197(85)$ \\
Patient expectations & $191(82)$ \\
Patient's charter & $146(63)$ \\
Staff attitude & $129(55)$ \\
Illness & $94(40)$ \\
Medical TV & $41(18)$ \\
\hline
\end{tabular}

\section{Discussion}

This survey targeted 273 consultants in charge of $A \& E$ departments. It was felt that they were the most appropriate people to question because they should know most about their security measures as well as being informed about ongoing legal action and outcomes. Staffing and functions of $A \& E$ departments are the same in the UK and Ireland, with consultants from both countries involved in the umbrella organisations (British Association for Accident \& Emergency Medicine and Faculty of Accident \& Emergency Medicine).

About three quarters of $A \& E$ departments and $80 \%$ of consultants replied. We believe this indicates the high level of concern about these problems; in addition, we feel that the high response gives a fair reflection of the situation throughout the two islands. The responses strongly suggest that these problems are extremely widespread and that anecdotal reports in the press only represent the tip of the iceberg.

Panic buttons and video cameras were the most commonly used security measures. It was surprising to note that 14 departments had no security measures at all in their departments. Of these 14 departments only five had no episodes of physical violence. About three quarters of departments had three or fewer security measures available.

Because a significant number of $A \& E$ departments did not record specific episodes of both physical and verbal abuse, the overall figures in this survey must represent an underestimate; that being the case, they may reasonably be taken as a good indication of the real frequency of these episodes and must be a matter of serious concern for the majority of hospitals in the British Isles. Only a small minority of consultants $(10 \%)$ had no experience of physical violence in their departments.

Soft tissue injuries (contusions and abrasions) were the most common injuries sustained, lacerations, and fractures less so. Members of staff required time off work on 106 occasions. There were about 15000 recorded episodes of verbal and physical abuse; 298 people were arrested, with about one third of these going to court, and a subsequent three quarters of these leading to a conviction. This equates to an arrest rate of 1:50 and a conviction rate of about 1:200 of recorded episodes. Given that many incidents were not recorded, the actual ratios must be even greater than these, suggesting that there may be a high level of tolerance or even reluctance to press for conviction by employing authorities.

It must come as no surprise that the main recipients of abuse are nurses. Patients and their relatives, who seem quite prepared to be rude and often offensive to nurses, are usually much less aggressive when the doctor arrives. ${ }^{4}$ Episodes of physical attack are perhaps more spontaneous and more likely to involve medical staff, although nurses are still more often affected. This is probably because of the physical nearness nurses and doctors have to patients, whereas receptionists are often 
protected from physical attack, but not from verbal abuse, by glass screens.

While it seems that patients themselves are the main miscreants, ${ }^{5}$ their friends and relatives may also be involved and it may be that these episodes often occur because people are ill or anxious about their own or their companions' wellbeing. Nevertheless such behaviour surely cannot be excused. If patients have a right to expect staff to be courteous, staff must have the same expectations of patients and accompanying persons.

Documentation of incidents, both verbal and physical, is important in defining the extent of this problem. ${ }^{56}$ In addition, it can only be sensible to do so in today's climate of complaint and litigation. It perhaps reflects the "normality" of verbal abuse within A\&E departments that only $16 \%$ always record an incident and that $61 \%$ of departments did not have written guidelines for dealing with this problem. Unsurprisingly, acts of physical violence are more likely to be recorded and more departments have written policies for dealing with this.

It is of no surprise that alcohol is perceived as being the most likely precipitating factor of abuse. Waiting times, drugs, and patient expectations were ranked second, third, and fourth respectively. The advent of medical television dramas and informative programmes does not seem to be important in this respect but there is a perception that the patient's charter has had a significant effect on patients' expectations. It seems likely that increased levels of abusive behaviour have had a detrimental effect on staff morale but other relevant factors, for example NHS funding and reform and staff shortages in $A \& E$ departments have not been measured.

\section{Conclusion}

The strong impression gleaned from this survey is that, for many $A \& E$ departments, verbal abuse and physical assaults on staff are a major problem. There is under-recording of these incidents and a sense that abuse of staff is not taken seriously enough by management.
Serious injuries do occur and significant numbers of working days are lost. There are few arrests and even fewer prosecutions.

Although, given the nature of the work of $A \& E$ departments and the sort of patients sometimes attending, it seems unlikely that this problem can be totally eliminated, we believe there are a number of measures that trusts should be implementing to try, as far as possible, to improve the current unsatisfactory situation. All departments should have written policies for dealing with abusive patients and accompanying persons. In addition, each episode should be documented-this would demonstrate the exact nature of the problem in any given department and add weight to requests for action to deal with it. All staff should receive training in methods to deal with difficult and aggressive people and to try to defuse potentially troublesome situations; they may even require training in self defence and breakaway techniques. Staffing levels, especially for doctors, should be optimised to ensure the shortest possible waits for patients. Departments should be designed or altered to allow staff to exclude troublesome relatives or others from the clinical areas and, as far as possible, to provide pleasant and comfortable waiting areas. Patients and relatives should always be kept informed about their ongoing management and likely waiting times. Where required, trusts must initiate some or all of the recognised security measures and, very importantly, must show their staff that they are prepared to give them unstinting support in terms of identification, exclusion, and even prosecution of offenders.

1 Wyatt JP, Watt $M$. Violence towards junior doctors in accident and emergency departments. J Accid Emerg Med 1995;12:40-2.

2 Schneiden V, Marren-Bell U. Violence in the accident and emergency department. Accid Emerg Nurs 1995;3:74-8.

3 Bache J. [Letter.] The Magistrate 1995;51(3):65.

4 Cembrowicz SP, Shepherd JP. Violence in the accident and emergency department. Med Sci Law 1992;32:118-22.

5 Schneiden V, Marren-Bell U. [Letter.] Arch Emerg Med 1992;9:330-1.

6 Lanza ML. Nurses as patient assault victims: an update, synthesis, and recommendations. Arch Psychiatr Nurs 1992;VI(3):163-71 